\title{
Process modeling and evaluation of petroleum refinery wastewater treatment through response surface methodology and artificial neural network in a photocatalytic reactor using poly ethyleneimine (PEI)/titania $\left(\mathrm{TiO}_{2}\right)$ multilayer film on quartz tube
}

\author{
Parvaneh Pakravan • Aazam Akhbari • \\ Hojatollah Moradi • Abbas Hemati Azandaryani • \\ Amir Mohammad Mansouri • Mojtaba Safari
}

Received: 2 May 2014/ Accepted: 11 July 2014/Published online: 15 August 2014

(C) The Author(s) 2014. This article is published with open access at Springerlink.com

\begin{abstract}
In this study, poly ethyleneimine (PEI)/Titania $\left(\mathrm{TiO}_{2}\right)$ multilayer film on quartz tubes have been successfully fabricated via a layer-by-layer (LbL) self-assembly method. Scanning electron microscopy (SEM) and Brunauer-Emmett-Teller (BET) surface area analysis were carried out for characterization of the layers on quartz tube. The SEM pictures showed that the film surface is smooth and uniform. The BET characterization verified the formation of multilayer thin film. The photocatalytic activity of the PEI/TiO ${ }_{2}$ multilayer deposited on the quartz tubes was evaluated in the treatment of raw petroleum refinery wastewater (PRW) under UV light irradiation in three annular photocatalytic reactors. This study examined the impact of initial chemical oxygen demand (COD) concentration, $\mathrm{H}_{2} \mathrm{O}_{2}$ concentration, $\mathrm{pH}$ and reaction time on the PRW treatment and the results were used to generate both a response surface methodology (RSM) model and an artificial neural network (ANN) model. Maximum COD
\end{abstract}

\section{P. Pakravan}

Department of Chemistry, Zanjan Branch, Islamic Azad

University, Zanjan, Iran

A. Akhbari · A. M. Mansouri ( $\square)$

Department of Analytical Chemistry, Faculty of Chemistry,

Razi University, Kermanshah, Iran

e-mail: ammansouri@yahoo.com

A. Akhbari

e-mail: aazam.akhbari@yahoo.com

H. Moradi

Department of Chemical Engineering, Razi University,

Kermanshah, Iran

A. H. Azandaryani

Department of Applied Chemistry, Faculty of Chemistry,

Razi University, Kermanshah, Iran removal (98\%) was achieved at the optimum conditions (initial COD concentration of $300 \mathrm{mg} / \mathrm{l}$, hydrogen peroxide concentration of $8.8 \mathrm{mM}, \mathrm{pH}$ of 5 and reaction time of $120 \mathrm{~min})$. A comparison between the model results and experimental data gave a high correlation coefficient $\left(R_{\mathrm{ANN}}^{2}=0.9632, R_{\mathrm{RSM}}^{2}=0.943\right)$ and showed that two models were able to predict COD removal from PRW by $\mathrm{PEI} / \mathrm{TiO}_{2} / \mathrm{UV}$ process. However, ANN model was superior to RSM model with higher value of coefficient of determination $\left(0.9632_{\mathrm{ANN}}>0.94_{\mathrm{RSM}}\right)$ and the lower root mean square error $(\mathrm{RMSE})\left(3.377_{\mathrm{AAN}}<3.569_{\mathrm{RSM}}\right)$. The average percentage error for ANN and RSM models was 0.18 and 0.73 , respectively, indicating the superiority of ANN in capturing the nonlinear behavior of the system. It was clear that the best networks were able to predict the experimental responses more accurately than the multiple regression analysis.

\section{A. H. Azandaryani \\ Nano Drug Delivery Research Center, Kermanshah University of Medical Science, Kermanshah, Iran}

A. M. Mansouri

Research Center for Environmental Determination of Health (RCEDH), Kermanshah University of Medical Science,

Kermanshah, Iran

M. Safari

Department of Chemical Engineering, Amirkabir University, Tehran, Iran 
Keywords Petroleum refinery wastewater - Response surface methodology · Artificial neural network · Layer-bylayer self-assembly

\section{Introduction}

The petroleum refinery and petrochemical industries are two of the largest industries in Iran [8]. Wastewater generated by petroleum industries is very complex, and includes several inorganic and organic components, such as emulsified oil, sulfides, ammonia, cyanides and especially phenol and phenolic derivatives [41]. Due to the nature of the pollutants included in petrochemical and oil refinery wastewater, its treatment is a challenging issue and several different physical-chemical, mechanical and even biological conventional treatment processes have been tested for its restoration in the past.

A wide diversity of procedures, such as API separators, specific biological systems, ultra-filtration, fenton and photo fenton processes [8], absorption [39] and other methods [34, 36] have been used for the reduction of chemical oxygen demand (COD), total petroleum hydrocarbon (TPHs), biochemical oxygen demand (BOD5) and many others in the effluent with some success.

Although these conventional techniques have been commonly used, there are several drawbacks [31]. The main drawback of these techniques relates to the disposal of the spent contaminated activated sludges, generation of toxic by-products, severe operation conditions (e.g., high temperature and high pressure) and the slow reaction rates, which mean higher energy consumption and expensive running cost.

In the last decade, advanced oxidation processes (AOPs) including heterogeneous (i.e., semiconductors such as $\mathrm{TiO}_{2}$ and $\mathrm{ZnO}$ in the presence of UV light) and homogenous (i.e., Fenton's reagent, $\mathrm{H}_{2} \mathrm{O}_{2}$ and ozone) processes have gained the interest of researchers for the elimination of dangerous organic pollutants from various wastewaters [19]. Among AOPs, $\mathrm{TiO}_{2}$ has been widely used because of its various merits such as low toxigenicity, relative low cost, favorable band gap energy, high chemical stability and activity [37].

In previous studies, the majority of experiments to date have used small $\mathrm{TiO}_{2}$ particles suspended in the discontinuous slurry photoreactors. However, these reactors have many practical and economical disadvantages related to the filtration and reuse of the catalyst and also the inefficient illumination of the particles, resulting in an actually higher operating cost and lower reactivity, respectively. Moreover, recent studies have raised concerns about the potential toxicity of titanium dioxide nanoparticles. Consequently, many research efforts have been dedicated to the development of immobilized systems following different approaches, synthesis routes and support materials [1, 26]. Catalyst can be immobilized with various procedures such as, sputtering, dip coating, sol-gel synthesis, and chemical vapor deposition method, spin coating, etc. Among these techniques, the layer-by-layer self-assembling (LBL-SA) method that was pioneered by Decher [24], is a simple and effective method for constructing organic/inorganic films via alternate deposition of components (polyelectrolytes or nanoparticles) with opposite electrical surface charge or hydrogen-bonding groups from dilute solutions [10].

The conventional "one-factor-at-a-time" approach is laborious and time consuming. Moreover, it seldom guarantees the determination of optimal conditions. These limitations of a single factor optimization process can be overcome by using empirical methods. Recently, response surface methodology (RSM) and artificial neural network (ANN) methods have been used jointly for both modeling and optimization purposes in environmental studies.

Response surface methodology is a series of experimental design, analysis, and optimization techniques that originated in the work by Box and Wilson in 1951 [6]. The main idea of response surface methodology is to optimize an unknown and noisy function by means of simpler approximating functions that are valid over a small region using designed experiments. By moving the operating conditions of a process using a sequence of experimental designs, process improvement is achieved. Response surface methodology has important applications in industrial designing, developing, and improving existing product. It also can be useful for the formulation of new products. It defines the effect of the controlling or independent variables, alone and in combination on the response, in the processes [3, 7, 20, 21, 23, 27, 33, 40].

With the interdisciplinary development of modern computational technologies, artificial neural networks (ANNs), as typical artificial intelligence (AI) algorithms, have become an attractive approach for modeling highly complicated and nonlinear system [12, 38, 43]. The ANN can be described as a group of simple processing elements called neurons arranged in parallel layers that are fully interconnected by weighted connections. One of the most important characteristics of neural networks is learning. Artificial neural networks have two operation modes, training mode and normal mode [30]. In training mode, adjustable parameters of the networks are modified. In normal mode, the trained networks are applied for simulating the outputs [30].

An ANN attempts to learn the relationships between the input and output data sets in the following way: during the training phase, input/output data pairs, called training data, are introduced into the neural network. The difference between the actual output values of the network and the 
training output values is then calculated. The difference is an error value which is decreased during the training by modifying the weight values of the connections. Training is continued iteratively until the error value has reached the predetermined training goal [22].

It is believed that ANN would require much more number of experiments (number of patterns) than RSM to build an efficient model. But in fact, the ANN can also work well even with relatively less data, if the data are statistically well distributed in the input domain, which is the case with DOE. This experimental data of RSM should be sufficient to build effective ANN model. There are few case studies available in the literature where models were developed by RSM and ANN using same DOE; and ANN models have consistently worked better than RSM [5, 12, 17].

The major advantages of ANN compared to RSM are (1) it does not need a prior specification of appropriate fitting function and (2) ANN is capable of universal estimation, i.e., ANN can estimate nearly all types of nonlinear functions such as quadratic functions, where RSM is suitable only for quadratic estimations [9].

In this study, poly (ethyleneimine) (PEI)/titania $\left(\mathrm{TiO}_{2}\right)$ multilayer film on quartz tubes was assembled through the layer-by layer (LbL) self-assembly method and were applied in PRW treatment and characterization methods were carried out for determination of the morphology and roughness of the prepared thin films on quartz tube. Then ANN and RSM have been used to compare the performances of the statistical- and artificial intelligence-based optimization techniques. The predictive models given by RSM and ANN have also been compared for their experimental and predicted response factor values, lower root mean square error (RMSE), average error percentage (Er \%), and coefficients of determination $\left(R^{2}\right)$.

\section{Experimental}

\section{Materials}

The chosen catalyst of $\mathrm{TiO}_{2}$, mainly anatase $(90 \%$ anatase and $10 \%$ rutile, Degussa $\mathrm{P} 25$ ) with a particle size of $30 \mathrm{~nm}$ and Cationic poly (ethyleneimine) (PIA, $\mathrm{MW}=7.5 \times 10^{5} \mathrm{~g} / \mathrm{mol}$ ) were both purchased from Aldrich and used as-received (Sigma, St. Loius, MO, USA). Hydrogen peroxide (30 \%, v/v) was obtained from Merck Co. (Darmstadt, Germany). Sulfuric acid and sodium hydroxide (Merck Co. Darmstadt, Germany) solutions were used to adjust the $\mathrm{pH}$ of wastewater samples. For dipping solutions of the LBL-SA method,PIA polymers were dissolved in DI water to the concentration of $0.01 \mathrm{M}$. The $\mathrm{pH}$ of the solution was also adjusted with $\mathrm{HCl}$ and $\mathrm{NaOH}$ to the required $\mathrm{pH}$.
Preparation of multilayered film by the LbL technique

Quartz tubes were cleaned by immersing them in the mixture of methanol and concentrated $\mathrm{HCl}(1: 1)$ for $30 \mathrm{~min}$ and then in the piranha solution $(70 / 30 \mathrm{v} / \mathrm{v}$ of concentrated $\mathrm{H}_{2} \mathrm{SO}_{4}$ and $30 \% \mathrm{H}_{2} \mathrm{O}_{2}$ ) to create negatively charged surfaces for $24 \mathrm{~h}$. The substrate was finally rinsed several times with DI water and then dried with $\mathrm{N}_{2}$ flushing. To make a doping solution for the LBL-SA process, $\mathrm{TiO}_{2}$ nanoparticles were dispersed in DI water $(\mathrm{pH} 8)$ to yield a $0.1 \%$ wt. transparent solution in which $\mathrm{TiO}_{2}$ nanoparticles had a negatively charged surface [31].

Layer-by-layer self-assembled thin films were fabricated by sequential deposition of oppositely charged polymer and $\mathrm{TiO}_{2}$ nanoparticles at room temperature. For a single nanoparticle layer in the film, for example, a negatively charged substrate was sequentially dipped in a cationic PEI $(0.01 \mathrm{M})$ and then in ananionic $\mathrm{TiO}_{2}$ solution (0.1 wt. \%), yielding a $\left(\mathrm{PEI} / \mathrm{TiO}_{2}\right)$ thin film. By controlling this dipping sequence, LBL-SA thin films of $\mathrm{PEI} / \mathrm{TiO}_{2}\left(\mathrm{PEI} / \mathrm{TiO}_{2}\right) n-1$ were fabricated with a desired number of $\mathrm{TiO}_{2}$ nanoparticle layers $(n)$. For each layer, the substrate was dipped into the solution for $15 \mathrm{~min}$, and washed by distilled water, and then dried in the temperature of $100{ }^{\circ} \mathrm{C}$.

\section{Photoreactor configuration}

Figure 1 shows the experimental setup of the photoreactor for the treatment of PR Win continuous mode operation. This photoreactor was equipped with three thin gap annular photocatalytic reactors in series with the working volume of $2,850 \mathrm{ml}$ [total liquid volume of each of photoreactor was $950 \mathrm{ml}$ excluding volume of the quartz tube (40 tubes in each of the reactor) inside the photoreactor]. The UV lamps (22 cm body length and $16 \mathrm{~cm}$ arc length) were mercury $400 \mathrm{~W}(200-550 \mathrm{~nm})$ lamps. The UV lamp was installed in the inner quartz tube of each reactor and was totally immersed in the reactor. Therefore, the maximum light utilization was achieved. At first, PRW flow flowed sequentially through each annular reactor one by one by means of peristaltic pump from the wastewater reservoir and subsequently discharged to the settling tank. Hydrogen peroxide was added to the first reactor at a certain concentration. This photoreactor was operated under room temperature $\left(22 \pm 2{ }^{\circ} \mathrm{C}\right)$. The air was introduced into the each reactor with a bubble air diffuser at the bottom of the each reactor, and the air flow rate was controlled with an air flow-meter connected to blower (aeration rate, 4 1/min). The laboratory tests were accomplished using the pretreated refinery wastewater samples (after flotation and coagulation). PRW was randomly collected from an oil refinery plant located in the city of Kermanshah, Iran. The COD and BOD5 of the PRW sample were about $750 \pm 60$ 


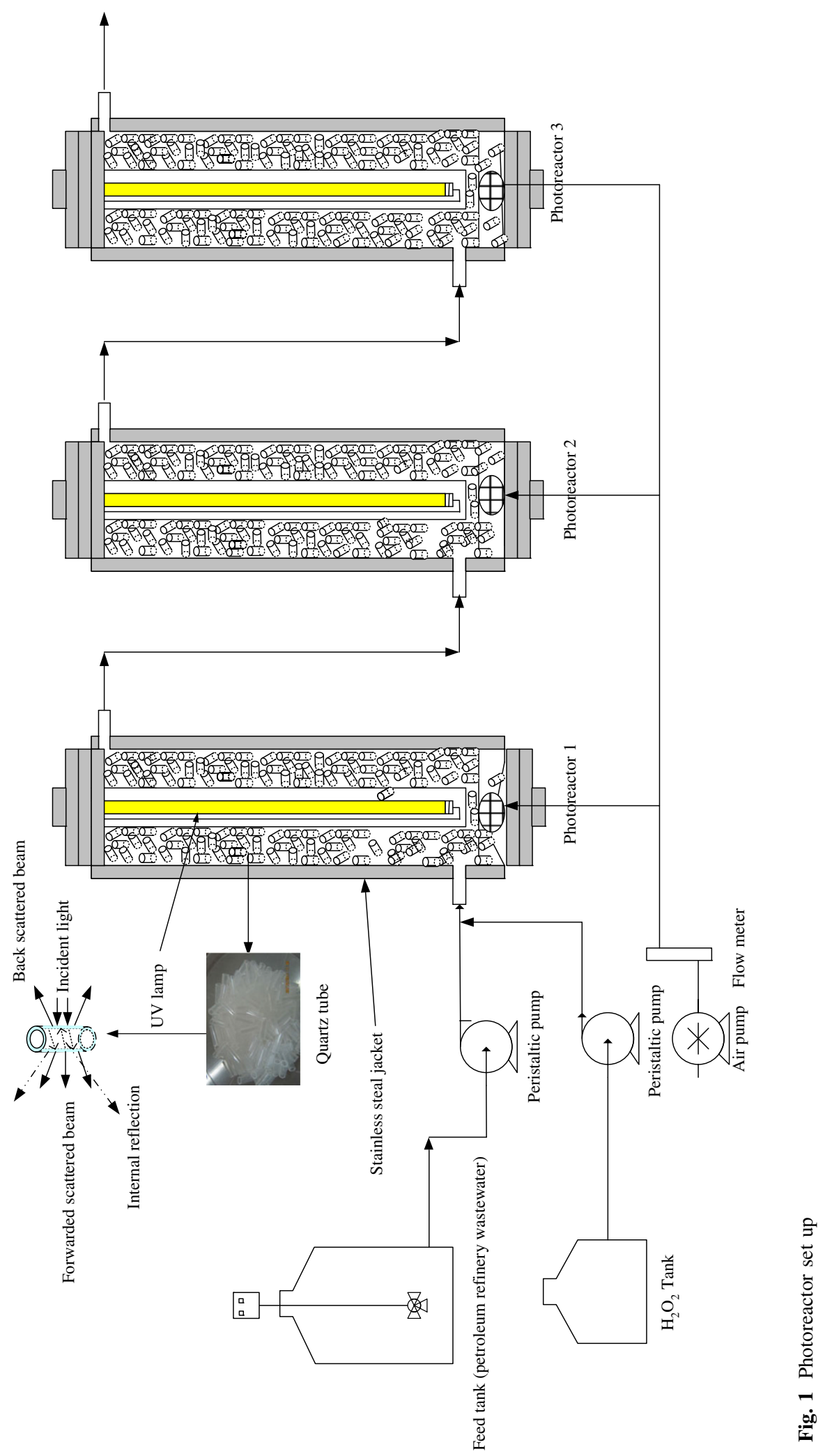


Fig. 2 The ANN optimized structure in three layered feedforward back propagation neural network for COD removal modeling

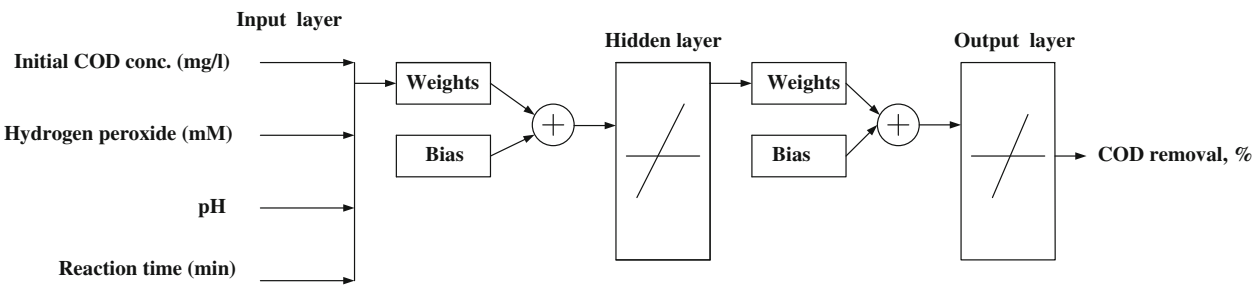

and $300 \pm 26 \mathrm{mg} / \mathrm{l}$, respectively, and it was diluted to the required initial concentrations. Other specifications were pH: 6.7, turbidity: $115 \mathrm{NTU}$, phenol concentration: $96 \mathrm{mg} / \mathrm{l}$ and total dissolved solids: $645 \mathrm{mg} / \mathrm{l}$. The concentrations of chemical oxygen demand (COD) and BOD were determined by using standard methods [4].

Characterization of the $\mathrm{PEI} / \mathrm{TiO}_{2}$ multilayer film

A surface morphology of $\mathrm{PEI} / \mathrm{TiO}_{2}$ thin films was studied by scanning electron microscopy using a Philips XL30 microscope at an accelerating voltage of $20 \mathrm{kV}$. After oven-drying of the thin film for $12 \mathrm{~h}$, the sample was coated with a platinum layer using an SCDOOS sputter coater (BAL-TEC, Sweden) in an argon atmosphere. Subsequently, the sample was scanned and photomicrographs were obtained. Also the surface properties of PEI/ $\mathrm{TiO}_{2}$ thin films were visualized using an atomic force microscope (Mobile S, Nanosurf, Switzerland). Explorer atomic force microscopy was in the noncontact mode, using high resonant frequency (F0 $170 \mathrm{kHz}$ ) pyramidal cantilevers with silicon probes having dynamic force.

$\mathrm{N}_{2}$ adsorption/desorption isotherms (BET) at $77 \mathrm{~K}$ were measured on Belsorp mini II (Bel Japan). Samples were placed in a tube under $\mathrm{N}_{2}$ atmosphere and then outgassed for $2 \mathrm{~h}$ at $80{ }^{\circ} \mathrm{C}$ prior to the measurements. X-ray diffraction (XRD) patterns of samples were recorded using EQUINOX diffractometer (Inel Company) operating with a $\mathrm{Cu}$ anode and a sealed X-ray tube. The $2 \theta$ scans were recorded at several resolutions using $\mathrm{CuK} \alpha$ radiation of wavelength $1.548 \AA$ in the range of $20-80$ with 0.05 step size.

\section{Predictive modeling and optimization methods}

Artificial neural network

A typical neural network structure used in this study is shown in Fig. 2. As shown in the figure, the ANN structure consists of an input layer (independent variables), hidden layer (hidden) and output layer (dependent variables), so that these layers are connected together by connections with different weights.

The task of the hidden layer makes a connection between input and output layer. One or more neurons can
Table 1 ANN training parameters

\begin{tabular}{ll}
\hline Parameter & Value \\
\hline Number of input nodes & 4 \\
Number of hidden neurons & 5 \\
Number of output node & 1 \\
Learning rule & Levenberg-Marquardt \\
Number of epochs & 1,000 \\
$\mu$ & 0.001 \\
\hline
\end{tabular}

Table 2 Model variables and their ranges. (the range of the data used for ANN)

\begin{tabular}{ll}
\hline Variable & Range \\
\hline Input layer & \\
Initial COD conc. $(\mathrm{mg} / \mathrm{l})$ & $300-800$ \\
Hydrogen peroxide $(\mathrm{mM})$ & $2.2-15.4$ \\
$\mathrm{pH}$ & $1.5-10.5$ \\
Reaction time (min) & $45-135$ \\
Output layer & \\
COD removal & $33.2-98$ \\
\hline
\end{tabular}

be putted in the hidden layers. Network with a hidden layer is capable of deriving the nonlinear equations from presented data belong to that.

The topology of an artificial neural network is determined by the number of its layers, number of nodes in each layer and the nature of transfer functions. The most important step in the development of the model probably is optimization of ANN topology. We used three layered feed-forward back propagation neural network (4:5:1) for modeling of COD removal (Fig. 2).

In this study, input variables to the feed-forward neural network were as follows: initial COD conc. (mg/l), hydrogen peroxide $(\mathrm{mM}), \mathrm{pH}$ and reaction time $(\mathrm{min})$. The percentage of COD removal was chosen as an experimental response or output variable. The training parameters and the range of the data used for ANN in this investigation are listed in Tables 1 and 2, respectively.

In this work, we tested different numbers of neurons, from 2 to 10, in the hidden layer. Each topology was repeated three times to avoid random correlation due to the random initialization of the weights. Table 3 demonstrates 
Table 3 Effect of the number of neurons in the hidden layer on the performance of the neural network

\begin{tabular}{lllll}
\hline Number of hidden neurons & $R^{2}$ & $R_{\text {adj }}^{2}$ & RMSE & SSE \\
\hline 2 & 0.5369 & 0.5204 & 0.07893 & 0.1754 \\
3 & 0.6797 & 0.6682 & 0.1051 & 0.3094 \\
4 & 0.7635 & 0.7551 & 0.06705 & 0.1259 \\
$\mathbf{5}$ & $\mathbf{0 . 9 6 3 2}$ & $\mathbf{0 . 9 6 1 9}$ & $\mathbf{0 . 0 3 3 7 7}$ & $\mathbf{0 . 0 3 1 4 4}$ \\
6 & 0.929 & 0.9215 & 0.04548 & 0.05794 \\
7 & 0.5754 & 0.5603 & 0.08869 & 0.2202 \\
8 & 0.676 & 0.6644 & 0.09395 & 0.2472 \\
9 & 0.4575 & 0.4381 & 0.1184 & 0.3925 \\
10 & 0.7991 & 0.7919 & 0.06959 & 0.1356 \\
\hline
\end{tabular}

the relation between the network error and the number of neurons in the hidden layer. The root mean square error (RMSE) and the sum of squared error (SSE) were used as the error function. RMSE and SSE measure the efficiency of the network according to the following equation:

$\mathrm{RMSE}=\sqrt{\frac{\sum_{i=1}^{n}\left(y_{i, \text { predic }}-y_{i, \exp }\right)^{2}}{n}}$

$\mathrm{SSE}=\sum_{i=1}^{n}\left(y_{i, \text { predic }}-y_{i, \exp }\right)^{2}$

Also in Table 3, we see the correlation coefficient which represents the ratio between the data predicted by the neural network and real data:

$R^{2}=1-\frac{\sum_{i=1}^{i=n}\left(y_{i, \text { predic }}-y_{i, \exp }\right)^{2}}{\sum_{i=1}^{i=n}\left(y_{i, \exp }-y_{\mathrm{m}}\right)^{2}}$ where $n$ is the number of data point, $y_{i, \text { predict }}$ the network prediction, $y_{i, \exp }$ experimental response, $y_{\mathrm{m}}$ average actual and $i$ is an index of data. We can see that the performance of the network stabilized after inclusion of an enough number of hidden units just about eleven. As can be seen from Table 3, the root mean square error and the sum of squared error are minimum just about five neurons. The highest correlation coefficient for the network was five hidden neurons, which was 0.9632 with the RMSE of 0.03377 and SEE of 0.03144 . The $\mathrm{R}^{2}$ value is in reasonable agreement with the " $R_{\text {adj }}^{2}$ " values of 0.9619 , showing a very good agreement between the predicted and actual data.

\section{Response surface methodology}

RSM is an empirical statistical modeling technique employed for multiple regression analysis using quantitative data obtained from properly designed experiments to solve multivariate equations simultaneously [23, 28, 29].

A central composite experimental design (CCD) for independent variables involving four numerical factors: initial COD concentration (a), initial $\mathrm{H}_{2} \mathrm{O}_{2}$ concentration (b), $\mathrm{pH}$ (c) and reaction time (d) were used. The independent variable selected for the optimization was COD removal. Regression analysis was performed on the data obtained from the experiments. After conducting the experiments, the relationship between the dependent and independent variables was calculated using the following equation $[2,15,18,19,44]$ :

Table 4 Estimated regression coefficients and corresponding to ANOVA results from the data of central composite design experiments before elimination of insignificant model terms

\begin{tabular}{lrllllllr}
\hline $\begin{array}{l}\text { Model } \\
\text { terms }\end{array}$ & $\begin{array}{l}\text { Coefficient } \\
\text { estimate }\end{array}$ & $\begin{array}{l}\text { Standard } \\
\text { error }\end{array}$ & $\begin{array}{l}\text { Sum of squares } \\
(\mathrm{SS})\end{array}$ & $\begin{array}{l}\text { Degree of freedom } \\
(\mathrm{DF})\end{array}$ & $\begin{array}{l}\text { Mean square } \\
(\mathrm{MS})\end{array}$ & $F$ value & Prob $>F$ \\
\hline $\mathrm{A}$ & -9.08 & 1.87 & $1,689.42$ & 1 & $1,689.42$ & 66.28 & $<0.0001$ & Significant \\
$\mathrm{B}$ & 3.78 & 1.12 & 292.61 & 1 & 292.61 & 11.48 & 0.0041 & Significant \\
$\mathrm{C}$ & -8.12 & 1.12 & $1,350.68$ & 1 & $1,350.68$ & 52.99 & $<0.0001$ & Significant \\
$\mathrm{D}$ & 5.85 & 1.12 & 701.85 & 1 & 701.85 & 27.54 & $<0.0001$ & Significant \\
$\mathrm{A}^{2}$ & -2.72 & 1.12 & 84.12 & 1 & 84.12 & 3.30 & 0.05 & Significant \\
$\mathrm{B}^{2}$ & -5.10 & 1.50 & 295.57 & 1 & 295.57 & 11.60 & 0.0039 & Significant \\
$\mathrm{C}^{2}$ & -11.92 & 1.50 & $1,616.36$ & 1 & $1,616.36$ & 63.41 & $<0.0001$ & Not significant \\
$\mathrm{D}^{2}$ & -1.45 & 1.50 & 24.00 & 1 & 24.00 & 0.94 & 0.3472 & Not significant \\
$\mathrm{AB}$ & 5.08 & 1.50 & 412.09 & 1 & 412.09 & 16.17 & 0.0011 & Significant \\
$\mathrm{AC}$ & -3.95 & 1.26 & 249.64 & 1 & 249.64 & 9.79 & 0.0069 & Significant \\
$\mathrm{AD}$ & -0.65 & 1.26 & 6.76 & 1 & 6.76 & 0.27 & 0.6141 & Not significant \\
$\mathrm{BC}$ & 1.70 & 1.26 & 46.24 & 1 & 46.24 & 1.81 & 0.1980 & Not significant \\
$\mathrm{BD}$ & -0.30 & 1.26 & 1.44 & 1 & 1.44 & 0.056 & 0.8153 & Not significant \\
$\mathrm{CD}$ & -2.32 & 1.26 & 86.49 & 1 & 86.49 & 3.39 & 0.05 & Significant \\
\hline
\end{tabular}


$Y=\beta_{0}+\beta_{i} X_{i}+\beta_{j} X_{j}+\beta_{i i} X_{i}^{2}+\beta_{j j} X_{j}^{2}+\beta_{i j} X_{i} X_{j}+\ldots$

where, $Y, i, j, \beta, X$ are chosen process response, linear coefficient, quadratic coefficient, regression coefficient and coded independent variables, respectively. Model terms are chosen or neglected based on the probability of error $(P)$ value with $95 \%$ confidence level. The results obtained from CCD were entirely examined by means of analysis of variance (ANOVA) by Design Expert software Table 4.

\section{Data preparation}

ANN model is good as interpolating data, but not extrapolating. Therefore, to achieve a valid ANN model, the data selected for training should cover the full range of input random variables. However, selection of appropriate algorithms and transfer functions is essential to design a suitable ANN model; otherwise, the output results will be unreliable. Transition function of Tausig has been used in the hidden layer and transition function of linear has been used in output layer.

Since the sigmoidal transfer function was used in the hidden layer, before the training, it is better that inputs and targets are scaled to always be in a specified range. Therefore, all data input $\left(Y_{i}\right)$ in the area of $0.1-0.9$ is normalized as follows $\left(Y_{\text {norm }}\right)$ :

$Y_{\text {norm }}=0.8\left(\frac{Y_{i}-Y_{i, \text { min }}}{Y_{i, \max }-Y_{i, \min }}\right)+0.1$

where $Y_{i, \min }$ and $Y_{i, \max }$ are extreme values of $Y_{i}$ [42]. After the training of the network, all output reverted to its original scale and then the response predicted by the empirical results were compared to experimental design.

\section{Results and discussion}

$\mathrm{PEI} / \mathrm{TiO}_{2}$ multilayer film characterization

The $\mathrm{LbL}_{-} \mathrm{TiO}_{2}$ thin films were characterized by SEM and AFM to evaluate the surface morphology and the effectiveness of the multilayer assembly technique.

Figure $3 \mathrm{a}, \mathrm{b}$ shows the top view surface morphology of $\mathrm{PEI} / \mathrm{TiO}_{2}$ thin films that were examined by scanning electron microscope. A close view surface of the film shows a flat and dense surface morphology of polyelectrolytes and distributed $\mathrm{TiO}_{2}$ nanoparticles embedded in the film.

Figure $3 \mathrm{c}$ showed the $\mathrm{N}_{2}$ adsorption/desorption isotherms for thin film. This adsorption isotherm is apparently classified as the type III isotherm [14]. On the other hand, for this kind of isotherm the gradient once decreased around $0.1-0.3$ of $\mathrm{P} / \mathrm{P}_{0}$ and then increased from 0.7 to 1.0 of $\mathrm{P} / \mathrm{P}_{0}$. These results suggest the presence of at least two steps of pore filling, one at very low $\mathrm{P} / \mathrm{P}_{0}$ associated with the pores of molecular dimensions for effectively trapping the light into the inner layers and the other at a $0.7-1.0$ of $\mathrm{P} / \mathrm{P}_{0}$ associated with pores involving quasi-multilayer formation that proved the formation of $\mathrm{PEI} / \mathrm{TiO}_{2}$ thin films which was our purpose [35]. The XRD results of coated $\mathrm{TiO}_{2}$ before and after coating did not show any significant changes in the structure of photocatalysts as a consequence of the coating and calcination processes (Fig. 3d).

The PEI/TiO 2 multilayer thin films were further examined by AFM to determine the surface roughness. Figure $3 e$ shows the image for a thin film sample. It was from topography scan forward that the roughness of the film was around $120 \mathrm{~nm}$. With an increase in the number of multilayers, the roughness of some parts of the surface amplified because of farther deposition of $\mathrm{TiO}_{2}$ in these sites, which is due to the increase in the amount of $\mathrm{TiO}_{2}$ deposited per each layer.

\section{Predictive modeling with ANN}

The design of experiments, which is used for training the network and respective experimental removal percentages is given in Table 5.

ANN-based process model was developed using the most popular feed-forward ANN architecture namely, multi-layer perceptron (MLP) with logistic sigmoidal function. The MLP network has four input nodes representing independent variables and one output node representing the COD removal (\%). The data partitioning as training set and test had been done to avoid over training and over parameterization. The training cycle was performed for varying numbers of neurons in the hidden layer and also for various combinations of ANN-specific parameter like learning rate, random initialization. The generalization capacity of the model was ensured by selecting the weights resulting in the least test set RMSE.

Figure 3 shows a comparison between calculated and experimental values of the output variable for data set by using neural network model. Plot in this figure has correlation coefficient of 0.951 and indicates the reliability of the model.

The generalization and predictive capabilities of both RSM and ANN were compared. ANN model was superior to RSM mode with higher value of coefficient of determination $\left(0.9632_{\mathrm{ANN}}>0.94_{\mathrm{RSM}}\right)$ and lower root mean square error (RMSE) $\left(3.377_{\mathrm{AAN}}<3.569_{\mathrm{RSM}}\right)$. Desai et al. [9] have also reported the average percentage error for ANN and RSM models and the CC after employing ANN with genetic algorithm approach for optimization of fermentation process parameters, the results indicating the superiority of ANN in capturing the nonlinear behavior of the system. 
(a)

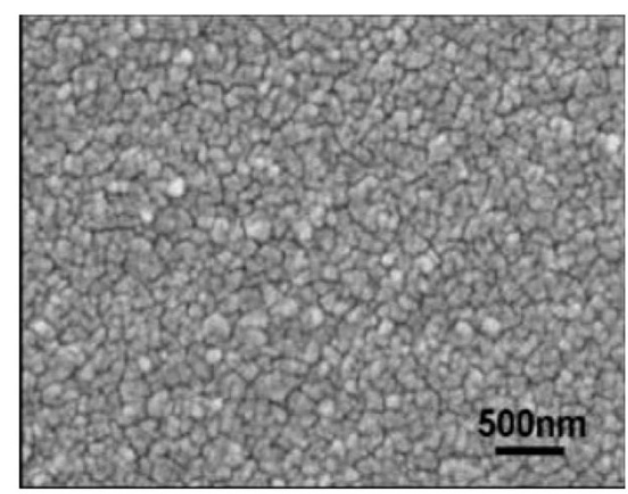

(c)

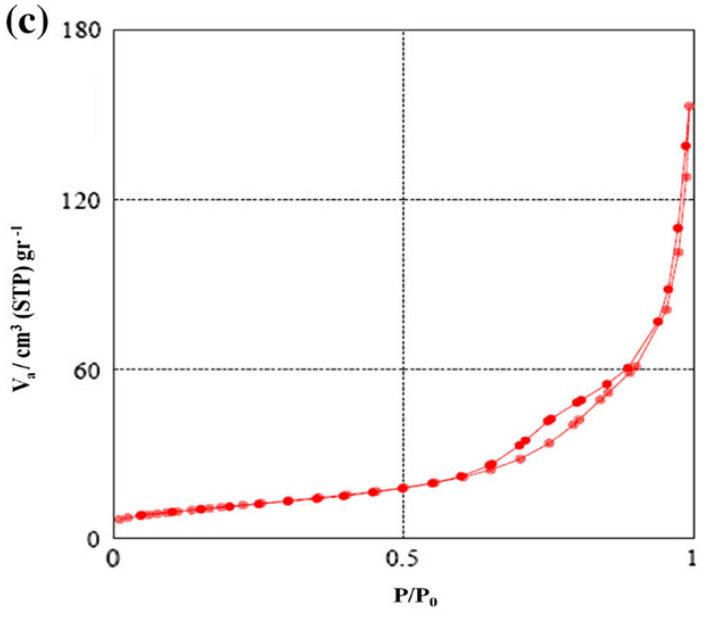

(e)

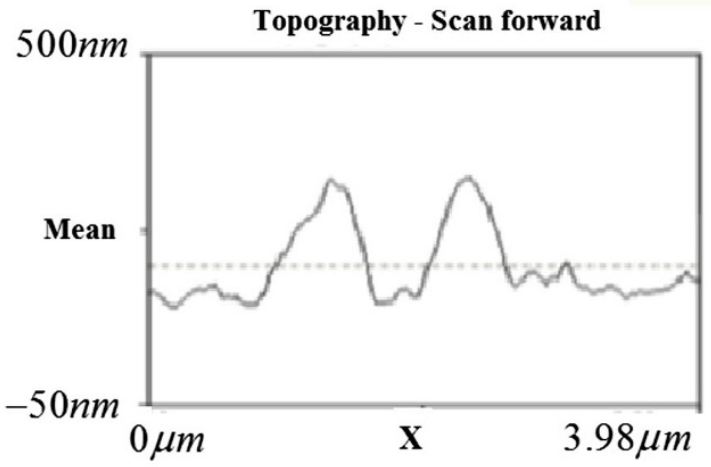

(b)

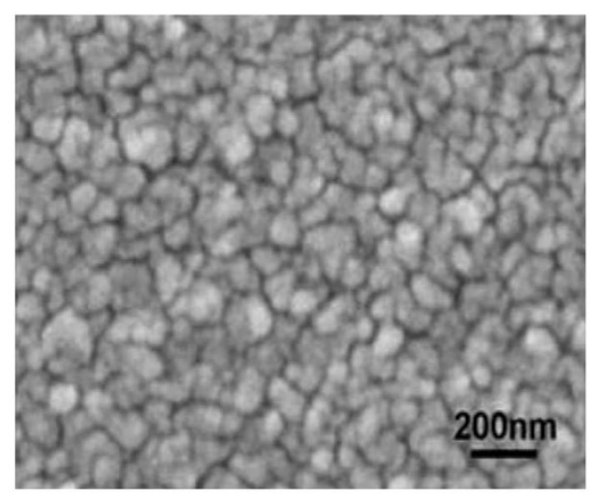

(d)

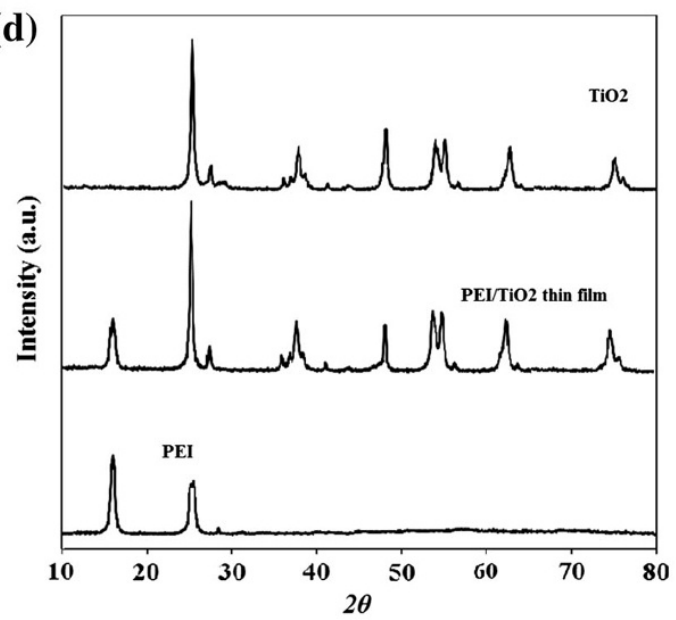

$3.98 \mu \mathrm{m}$ Topography - Scan forward

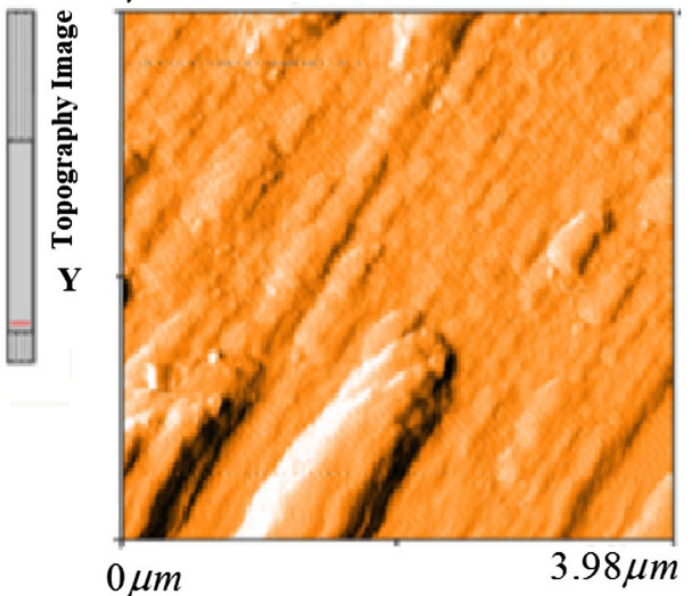

Fig. 3 SEM images: a $20 \mathrm{kV}, \times 20 \mathrm{~K}$, b $20 \mathrm{kV}$, $\times 50 \mathrm{~K}$, c N $\mathrm{N}_{2}$ adsorption/desorption isotherms for the PEI/TiO2 multilayers thin film, d X-ray diffraction patterns of samples and e AFM image

Response surface methodology

To examine the combined effect of four different independent variables, on COD removal, a central composite factorial design of $2^{4}=16$ plus 6 centre points and $(2 \times 4=8)$ star points leading to a total of 30 experiments were performed. Second-order polynomial equation was used to correlate the independent process variables, with COD removal. The second-order polynomial coefficient for each term of the equation determined through multiple regression analysis using the Design Expert. The same DoE, which used in ANN-based model development, was 
Table 5 Central composite design (CCD) matrix of independent variables and their corresponding experimental and predicted values

\begin{tabular}{|c|c|c|c|c|c|c|c|}
\hline \multirow[t]{2}{*}{ No } & \multicolumn{4}{|l|}{ Variables } & \multicolumn{3}{|l|}{ Response } \\
\hline & $\begin{array}{l}\text { Factor } 1 \text { initial COD conc. } \\
(200-800 \mathrm{mg} / \mathrm{l})\end{array}$ & $\begin{array}{l}\text { Factor } 2 \text { hydrogen peroxide } \\
(2.2-15.4 \mathrm{mM})\end{array}$ & $\begin{array}{l}\text { Factor } 3 \\
\mathrm{pH}(1.5-10.5)\end{array}$ & $\begin{array}{l}\text { Factor } 4 \text { reaction time } \\
(45-135 \mathrm{~min})\end{array}$ & Experimental & $\begin{array}{l}\text { RSM } \\
\text { predicted } \\
\text { COD } \\
\text { removal } \\
(\%)\end{array}$ & $\begin{array}{l}\text { ANN } \\
\text { predicted }\end{array}$ \\
\hline 1 & 500 & 8.8 & 6 & 90 & 91 & 90.24 & 87.43 \\
\hline 2 & 500 & 8.8 & 6 & 45 & 81.5 & 78.19 & 81.76 \\
\hline 3 & 200 & 8.8 & 6 & 90 & 98 & 97.74 & 97.22 \\
\hline 4 & 500 & 2.2 & 6 & 90 & 72 & 73.10 & 71.45 \\
\hline 5 & 700 & 13.2 & 9 & 120 & 59.5 & 61.03 & 59.54 \\
\hline 6 & 500 & 15.4 & 6 & 90 & 89.1 & 84.44 & 88.93 \\
\hline 7 & 500 & 8.8 & 6 & 90 & 80.7 & 90.24 & 87.43 \\
\hline 8 & 700 & 4.4 & 9 & 120 & 44 & 40.53 & 42.38 \\
\hline 9 & 700 & 4.4 & 3 & 120 & 68 & 72.71 & 68.07 \\
\hline 10 & 700 & 13.2 & 3 & 120 & 87.2 & 86.42 & 86.95 \\
\hline 11 & 500 & 8.8 & 6 & 90 & 89 & 90.24 & 87.43 \\
\hline 12 & 300 & 4.4 & 9 & 120 & 77 & 78.03 & 81.94 \\
\hline 13 & 300 & 13.2 & 9 & 60 & 75.5 & 70.49 & 75.98 \\
\hline 14 & 700 & 13.2 & 9 & 60 & 50 & 55.88 & 50.09 \\
\hline 15 & 500 & 8.80 & 1.5 & 90 & 75 & 75.60 & 77.07 \\
\hline 16 & 300 & 13.2 & 9 & 120 & 74.7 & 78.24 & 74.97 \\
\hline 17 & 300 & 4.4 & 3 & 60 & 78 & 76.17 & 79.66 \\
\hline 18 & 500 & 8.8 & 6 & 90 & 86 & 90.24 & 87.43 \\
\hline 19 & 500 & 8.8 & 6 & 90 & 93.5 & 90.24 & 87.43 \\
\hline 20 & 300 & 4.4 & 9 & 60 & 66 & 69.08 & 65.69 \\
\hline 21 & 300 & 13.2 & 3 & 60 & 65 & 70.77 & 67.96 \\
\hline 22 & 700 & 4.4 & 9 & 60 & 33.2 & 34.18 & 22.73 \\
\hline 23 & 500 & 8.8 & 6 & 90 & 95 & 90.24 & 87.43 \\
\hline 24 & 300 & 13.2 & 3 & 120 & 89.1 & 87.82 & 89.81 \\
\hline 25 & 500 & 8.8 & 6 & 135 & 96 & 95.75 & 98.53 \\
\hline 26 & 700 & 4.4 & 3 & 60 & 58.3 & 57.06 & 60.07 \\
\hline 27 & 700 & 13.2 & 3 & 60 & 73.3 & 71.97 & 71.92 \\
\hline 28 & 300 & 4.4 & 3 & 120 & 98 & 94.42 & 99.71 \\
\hline 29 & 500 & 8.8 & 10.5 & 90 & 55.4 & 51.24 & 56.45 \\
\hline 30 & 800 & 8.8 & 6 & 90 & 73.8 & 70.50 & 73.90 \\
\hline
\end{tabular}

also used to build the RSM model. The results were analyzed by using ANOVA, i.e., analysis of variance suitable for the experimental design. The results are shown in Table 4. The Model F-value of 66.28 implies that the model is significant. Model F-value is calculated as ratio of mean square regression and mean square residual. Model $P$ value $($ Prob $>$ F) is very low $(0.0001)$. This resignifies the significance of the model [9].

The $P$ values were used as a tool to check the significance of each of the coefficients, which, in turn, are necessary to understand the pattern of the mutual interactions between the test variables. The corresponding $P$ values, along with the coefficient estimate, are given in Table 4.

\section{Comparison of RSM and ANN}

\section{Predictive capabilities}

The ANN and RSM model were compared for DoE, using which the both models were prepared. The comparison was made on the basis of various parameters such as average percentage error, RMSE and $R^{2}$. Korany et al. [16] compared experimental and predicted response factor values, mean of squares error (MSE), average error percentage $($ Er $\%)$ and squared coefficients of correlation $\left(r^{2}\right)$. Their results showed that the best networks were able to predict the experimental responses more accurately than the 


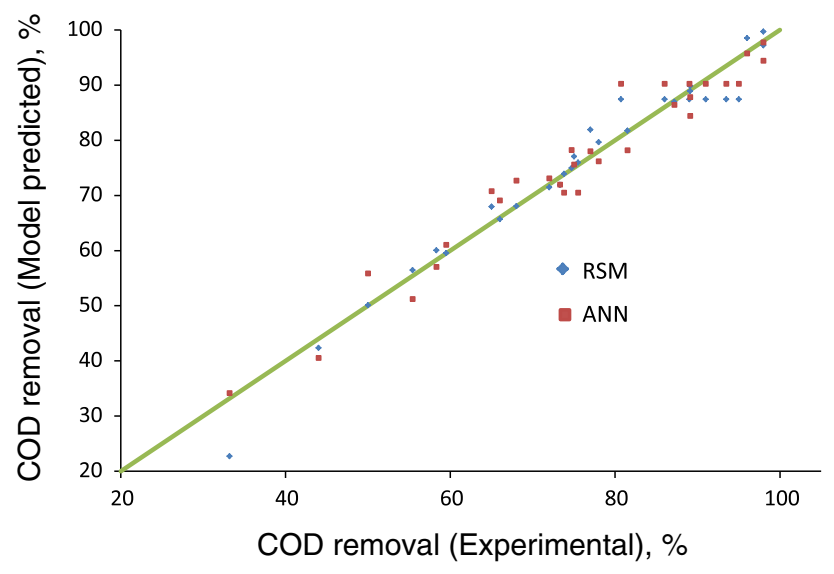

Fig. $4 R S M$ and $A N N$ predicted vs. experimental data

Table 6 Comparison of predictive capacity of RSM and ANN

\begin{tabular}{lll}
\hline Parameters & RSM & ANN \\
\hline RMSE & 3.569 & 3.377 \\
$R^{2}$ & 0.94 & 0.9632 \\
$R_{\text {adj }}^{2}$ & 0.91 & 0.9619 \\
Average \% error & 0.73 & 0.18 \\
\hline
\end{tabular}

multiple regression analysis. The predicted values by ANN as well RSM model are tabulated in Table 5.

Figure 4 shows the comparative parity plot for ANN and RSM predictions for DoE. The MLP-based model had fitted the experimental data with an excellent accuracy. This higher predictive accuracy of ANN can be attributed to its universal ability to approximate non-linearity of the system, whereas RSM only restricted to second-order polynomial. The comparative values average percentage error, RMSE and $R^{2}$ were given in Table 6 .

\section{Sensitivity analysis}

As shown in Table 4, the model term of $(A)$ has the largest coefficient (9.03) which indicates that COD concentration is the most dominating factor. This model term has significant effect on the system compared to other interactions. ANN being a black box model, it does not give such insights of the system directly. Black-box neural network model are allowed to acquire the relationships that exist between important variables and was used to predict the system variables. Except for a small network, it is almost impossible that the models describe the equations in the short-term and easily. Subsequently, the practical implementation of artificial neural networks is difficult. Desai et al. [9] found that ANN is equally efficient in sensitivity analysis and interestingly quite comparable to the coefficient of first-order terms in the quadratic RSM equation.
However, the nature of the black-box for ANN, one can perform sensitivity analysis for neural networks with different input variables on the results obtained from the model [32]. But there are numerous methods available which give the sensitivity analysis of the system using the inherent nature of ANN. Using Eq. 5, the effect of each input variable on the output variable modeling matrix was obtained by the network weight [11].

$I_{j}=\frac{\sum_{m=1}^{m=N_{h}}\left(\left(\left|W_{j m}^{j h}\right| / \sum_{k=1}^{N_{i}}\left|W_{k m}^{i h}\right|\right) \times\left|W_{m n}^{h o}\right|\right)}{\sum_{k=1}^{k=N_{h}}\left\{\sum_{m=1}^{m=N_{h}}\left(\left|W_{k m}^{i h}\right| / \sum_{k=1}^{N_{i}}\left|w_{k m}^{i h}\right|\right) \times\left|W_{m n}^{h o}\right|\right\}}$

where $I_{j}$ is the relative importance of the $j$ th input variable on the output variable, $N_{i}$ and $N_{h}$ are the numbers of input and hidden neurons, respectively; $W$ 's are connection weights, the superscripts ' $i$ ', ' $h$ ' and ' $o$ ' refer to input, hidden and output layers, respectively; and subscripts ' $k$ ', ' $m$ ' and ' $n$ ' refer to input, hidden and output neurons, respectively.

\section{Effect of the variables studied}

To gain a better understanding of the interaction effects of variables on COD removal efficiency, two and three dimensional contour plots for the measured response were formed based on the model (Eq. 4). Figure 5a shows the plots of the model for variation in COD removal as a function of initial COD concentration and reaction time for $\mathrm{H}_{2} \mathrm{O}_{2}$ concentration of $8.8 \mathrm{mM}$ and initial $\mathrm{pH}$ of 6 . It can be seen from Fig. 5a that the percentage of COD removal decreases as the initial concentration of the COD increases. The percentage removal was gradually decreased from $101.64 \%$ (with standard deviation of 4.92 ) to $71.8 \%$ as the COD concentration increased from 300 to $700 \mathrm{mg} / \mathrm{l}$. This can be explained in terms of either saturation of the limited number of accessible active sites on the photocatalyst surface that leads to a decrease in degradation efficiency, or poisoning (deactivation) of the active sites of the catalyst.

Three dimensional (3D) response surface and contour plots for COD removal as a function of initial $\mathrm{H}_{2} \mathrm{O}_{2}$ concentration and reaction time are presented in Fig. 5b. Such plots present the function of two variables, maintaining all others at the fixed levels (usually $X_{i}=0$ ). It could be seen from the figure that the degradation efficiency has increased by increasing the $\mathrm{H}_{2} \mathrm{O}_{2}$ concentration up to $8.8 \mathrm{mM}$ and then declined as $\mathrm{H}_{2} \mathrm{O}_{2}$ loading increased.

The effects of the $\mathrm{pH}$ and reaction time on the COD removal are shown in Fig. 5c. The examination of the figure shows that the $\mathrm{pH}$ of the emulsion has a crucial effect on performance. A reverse impact of the $\mathrm{pH}$ on COD removal was observed as the variable increased (Fig. 5c). As shown in this figure, an increase in $\mathrm{pH}$ (from 3 to 6) 

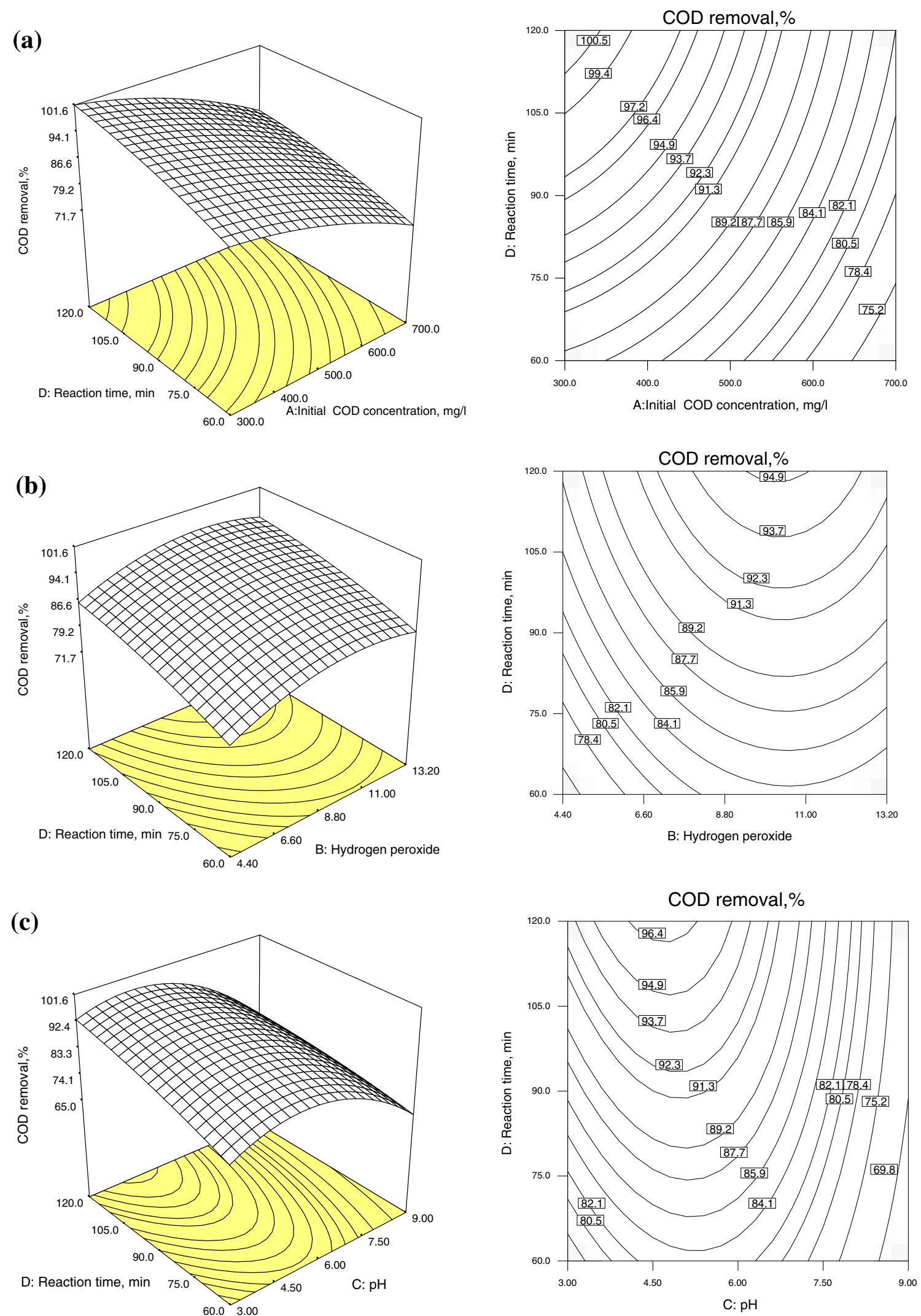

Fig. $53 \mathrm{D}$ and counter plots of COD removal efficiency (\%) as the function of a initial COD concentration and reaction time (min), b $\mathrm{H}_{2} \mathrm{O}_{2}$ $(\mathrm{mg} / \mathrm{l})$ and reaction time $(\mathrm{min})$ and $\mathbf{c} \mathrm{pH}$ and reaction time $(\mathrm{min})$ 
increases COD removal, while further increment in the variable (from 6 to 9) decreased the response. So, the optimum $\mathrm{pH}$ for COD removal was found to be in the range of 4.5-6. The pH-effect is related to the point of zero charge (pzc) of $\mathrm{TiO}_{2}$ at $\mathrm{pH} 6.2$ and charge of organic maters in different $\mathrm{pH}$ [25]. In acidic media $(\mathrm{pH}<6.2)$, the surface of $\mathrm{TiO}_{2}$ is positively charged, whereas it is negatively charged under alkaline conditions $(\mathrm{pH}>6.2)$.

Since the majority of organic maters in PRW are phenol and phenolic derivatives being negatively charged due to the $\mathrm{OH}$ groups which are ionized in water, their electrostatic attraction to the $\mathrm{TiO}_{2}$ surface is favorable in acidic solution and forbidden in alkaline media due to the columbic repulsion between the negatively charged surface of $\mathrm{TiO}_{2}$ and the organic molecules. From Fig. 5a-c, it can be seen that the most desirable operating conditions were initial COD concentration of $300 \mathrm{mg} / \mathrm{l}, \mathrm{H}_{2} \mathrm{O}_{2}$ concentration of $8 \mathrm{mM}, \mathrm{pH}$ of 5 and reaction time of $120 \mathrm{~min}$.

\section{Conclusion}

Poly ethyleneimine (PEI))/titania $\left(\mathrm{TiO}_{2}\right)$ multilayers films deposited on quartz tubes with smooth and uniform morphology were fabricated by LbL electrostatic self-assembly method. The $\mathrm{LbL} \mathrm{TiO}_{2}$ thin film was characterized by SEM and BET analyses. SEM images indicated that the film surface is smooth and uniform. The BET characterization method proved the multi-layer preparation. In continuation, the advantages of artificial neural network in comparison with response surface methodology were shown. By using central composite design, the number of required experiments was obtained. The predictive and generalization capabilities of both RSM and ANN were compared using separate dataset. The correlation coefficients for ANN and RSM were 0.96 and 0.94 , respectively. The modeling capability of ANN has shown its superiority over RSM with comparative less value of RMSE and average percentage error.

Open Access This article is distributed under the terms of the Creative Commons Attribution License which permits any use, distribution, and reproduction in any medium, provided the original author(s) and the source are credited.

\section{References}

1. Aguado J, van Grieken R, López-Muñoz MJ, Marugán J (2006) Appl Catal A Gen 312:202

2. Akhbari A, Zinatizadeh AL, Mohammadi P, Irandoust M, Mansouri Y (2011) Process modeling and analysis of biological nutrients removal in an integrated RBC-AS system using response surface methodology. Chem Eng J 168:269-279
3. Anjum MF, Tasadduq I, Al-Sultan K (1997) Response surface methodology: a neural network approach. Eur J Oper Res 101:65

4. APHA, WPCF, AWWA (1999) Standard methods for the examination of water and wastewater, 20th edn. American Public Health Association (APHA), Washington, DC

5. Bas D, BoyacI (2007) Modeling and optimisation. II. Comparison of estimation capabilities of response surface methodology with artificial neural networks in a biochemical reaction. J Food Eng 78:846-854

6. Castillo ED (2007) Process optimization a statistical approach, vol 97. Springer, New York

7. Chakraborty SK, Kumbhar BK, Sarkar BC (2007) Process parameter optimization for instant pigeon pea dhal using response surface methodology. J Food Eng 81:171

8. Coelho A, Castro AV, Dezotti M, Sant'Anna GL Jr (2006) Treatment of petroleum refinery sourwater by advanced oxidation processes. J Hazard Mater 137:178-184

9. Desai KM, Survase SA, Saudagar PS, Lele SS, Singhal RS (2008) Comparison of artificial neural network (ANN) and response surface methodology (RSM) in fermentation media optimization: case study of fermentative production of scleroglucan. Biochem Eng J 41:266-273

10. Decher G (1997) Computational design of hierarchically structured. Mater Sci 277:1232-1237

11. Garson GD (1991) Interpreting neural-network connection weights, AI Expert 6. pp 47-51

12. Ghaedi M, Abdi F, Roosta M, Sahraei R, Daneshfar A (2014) Principal component analysis-artificial neural network and genetic algorithm optimization for removal of reactive orange 12 by copper sulfide nanoparticles-activated carbon. J Ind Eng Chem 20:787-795

13. Ghaedi M, Zeinali N, Ghaedi AM, Teimuori M, Tashkhourian J (2014) Artificial neural network-genetic algorithm based optimization for the adsorption of methylene blue and brilliant green from aqueous solution by graphite oxide nanoparticle. Spectrochim Acta A Mol Biomol Spectrosc 125:264-277

14. Hwang N, Barron AR (2011) BET surface area analysis of nanoparticles. http://creativecommons.org/licenses/by/3.0/

15. Khuri AI, Cornell JA (1996) Response surfaces: design and analyses, 2nd edn. Marcel Dekker, New York

16. Korany A, Mahgoub H, Fahmy T, Maher M (2012) Application of artificial neural networks for response surface modeling in HPLC method development. J Adv Res 3:53-63

17. Lou W, Nakai S (2001) Application of artificial neural networks for predicting the thermal inactivation of bacteria: a combined effect of temperature, $\mathrm{pH}$ and water activity. Food Res Int 34:573-591

18. Mansouri $\mathrm{Y}$, Zinatizadeh AA, Mohammadi $\mathrm{P}$, Irandoust $\mathrm{M}$, Akhbari A, Davoodi R (2011) Hydraulic characteristics analysis of an anaerobic rotatory biological contactor (AnRBC) using tracer experiments and response surface methodology (RSM). Korean J Chem Eng 28:1025-1031

19. Mason RL, Gunst RF, Hess JL (2003) Statistical design and analysis of experiments, eighth applications to engineering and science, 2nd edn. Wiley, New York

20. Madamba PS, Yabes RP (2005) Determination of the optimum intermittent drying conditions for rough rice (Oryza sativa L.). Lebensmittel-Wissenschaft undTecchnologie 38:157

21. Mendes LC, de Menezes HC, Aparecida M, da Silva AP (2001) Optimization of the roasting of robusta coffee (C. canephora conillon) using acceptability tests and RSM. Food Qual Prefer 12:153

22. Mohamed A, Korany, Hoda Mahgou, Ossama T, Fahmy, Hadir M (2012) Maher, Application of artificial neural networks for response surface modeling in HPLC method development. J Adv Res 3:53-63 
23. Myers RH, Montgomery DC (1995) Response surface methodology: process and product optimization using designed experiments. Wiley, New York

24. NeelaPriyaa D, Modakb JM, Trebše P, Zabarc R, Raichura AM, Ashok M (2011) Photocatalytic degradation of dimethoate using LbL fabricated $\mathrm{TiO}_{2}$ /polymer hybrid films. J Hazard Mater 195:214-222

25. Pera-Titus M, Garcia-Molina V, Baños MA, Giménez J, Esplugas S (2004) Degradation if chlorophenols by means of advanced oxidation processes: a general review. Appl Catal B Environ 47:219-256

26. Rachel A, Subrahmanyam M, Boule P (2002) Appl Catal B Environ 37:301

27. Rodrigues SF, Fernández AN (2007) Dehydration of melons in a ternary system followed by air-drying. J Food Eng 80:678

28. Roosta M, Ghaedi M, Daneshfar A, Sahraei R, Asghari A (2014) Optimization of the ultrasonic assisted removal of methylene blue by gold nanoparticles loaded on activated carbon using experimental design methodology. Ultrason Sonochem 21(1):242-252

29. Roosta M, Ghaedi M, Daneshfar A, Sahraei R (2014) Experimental design based response surface methodology optimization of ultrasonic assisted adsorption of safaranin $\mathrm{O}$ by tin sulfide nanoparticle loaded on activated carbon. Spectrochimic Acta A Mol Biomol Spectrosc 122:223-231

30. Salajegheh E, Gholizadeh S (2005) Optimum design of structures by an improved genetic algorithm using neural networks. Adv Eng Softw 36:757-767

31. Shahrezaei F, Mansouri Y, Zinatizadeh AAL, Akhbari A (2012) Process modeling and kinetic evaluation of petroleum refinery wastewater treatment in a photocatalytic reactor using $\mathrm{TiO}_{2}$ nanoparticles. Powder Technol 221:203-212

32. Schaap MG, Bouten W (1996) Modeling water retention curves of sandy soils using neural networks. Water Resour Res 32:3033-3040

33. Sharma GP, Prasad S (2006) Optimization of process parameters for microwave drying of garlic cloves. J Food Eng 75:441
34. Sun Y, Zhang Y, Quan X (2008) Treatment of petroleum refinery wastewater by microwave assisted catalytic wet air oxidation under low temperature and low pressure. Sep Purif Technol 62:565-570

35. Taniike T, Chammingkwan P, Thang VQ, Funako T, Terano M (2012) Validation of BET specific surface area for heterogeneous Ziegler-Natta catalysts based on $\alpha$ S-plot. Appl Catal A 437:24-27

36. TezcanUn U, Koparal AS, Ogutveren UB (2009) Electrocoagulation of vegetable oil refinery wastewater using aluminum electrodes. J Environ Manag 90:428-433

37. TorabiMerajin M, Sharifnia S, Hosseini SN, Yazdanpour $N$ (2013) Photocatalytic conversion of greenhouse gases $\left(\mathrm{CO}_{2}\right.$ and $\mathrm{CH}_{4}$ ) to high value products using $\mathrm{TiO}_{2}$ nanoparticles supported on stainless steel webnet. J Taiwan Inst Chem Eng 44:239-246

38. Wang L, Shao C, Wang H, Wu H (2006) Radial basis function neural networks-based modeling of the membrane separation process: hydrogen recovery from refinery gases. J Nat Gas Chem 15:230-234

39. Ugurlu M, Gurses A, Yalcin M, Dogar C (2005) Removal of phenolic and lignin compounds from bleached kraft mill effluent by fly ash and sepiolite. Adsorption 11:87-97

40. Yao N, Floros JD, Seetharamant K (2007) Optimisation of hard pretzel production. Int J Food Sci Technol 42:269

41. Yan L, Bo Ma H, Wan B, Wang Y, Chen Y (2011) Electrochemical treatment of petroleum refinery wastewater with threedimensional multi-phase electrode. Desalination 276:397-402

42. Zarei M, Niaei A, Salari D, Khataee AR (2010) J Electroanal Chem 639:167

43. Zhao B, Su Y (2010) Artificial neural network-based modeling of pressure drop coefficient for cyclone separators. Chem Eng Res Des 88:606-613

44. Zinatizadeh AAL, Mohamed AR, Abdullah AZ, Mashitah MD, Hasnain Isa M, Najafpour GD (2006) Process modeling and analysis of palm oil mill effluent treatment in an up-flow anaerobic sludge fixed film bioreactor using response surface methodology (RSM). Water Res 40:3193-3208 